\title{
Evaluation of the Effects of Aminonaphthoquinone Derivatives in Combination with Curcumin Against ER-positive Breast Cancer and Related Tumours
}

\author{
MELANIE C. PEREIRA ${ }^{1}$, RAUSHAAN MOHAMMED ${ }^{2}$, WILLEM A.L. VAN OTTERLO ${ }^{2,3}$, \\ CHARLES B. DE KONING ${ }^{2}$ and HAJIERAH DAVIDS ${ }^{1}$ \\ ${ }^{1}$ Department of Biochemistry \& Microbiology, Nelson Mandela Metropolitan University, Port Elizabeth, South Africa; \\ ${ }^{2}$ Molecular Sciences Institute, School of Chemistry, University of the Witwatersrand, Johannesburg, South Africa; \\ ${ }^{3}$ Department of Chemistry and Polymer Sciences, Stellenbosch University, Western Cape, South Africa
}

\begin{abstract}
Background/Aim: Combination therapies are often explored to treat cancer. The use of curcumin as an adjuvant to current chemotherapies has been reported, whilst aminonaphthoquinones have shown potential as anticancer agents in various tumour cell lines. This study aimed at screening synthetic aminonathoquinone derivatives (Rau 008, Rau 010, Rau 015 and Rau 018) alone and in combination with curcumin for anti-breast cancer activity. Materials and Methods: Combination effects were determined in MCF-7 breast cancer cells using combination index analyses. Synergistic anti-proliferative effects were further investigated in breast (MCF-7, MDA-MB-231), osteosarcoma (MG-63) and endometrial (HEC-1A) cancerderived cells. Results: Rau $015(15 \mu M)$ and curcumin (112.5 $\mu M$ ) significantly reduced MCF-7, MDA-MB-231 and MG-63 cell proliferation compared to individual treatment, indicating synergistic anti-proliferative effects. Rau 018 $(30 \mu M)$ and curcumin $(100 \mu M)$ displayed similar effects in MCF-7 and MG-63 cells. Conclusion: We report on the potential of Rau 015 or Rau 018 as anti-breast cancer agents when combined with curcumin.
\end{abstract}

Breast cancer is considerably the most commonly diagnosed cancer in women world-wide, ranking second to lung cancer in both sexes combined. Approximately 1.7 million women worldwide were diagnosed with breast cancer in 2012, accounting for $25 \%$ of all cancers diagnosed in women,

Correspondence to: Hajierah Davids, Ph.D., Department of Biochemistry \& Microbiology, Nelson Mandela Metropolitan University, Port Elizabeth, 6031, South Africa. Tel: +27 41504 2019, email: hajierah.davids@nmmu.ac.za

Key Words: Curcumin, aminonaphthoquinone, combination, antiestrogenic. correlating to $12 \%$ of the total number of cancer cases in men and women (1). Nearly two thirds of breast cancers are classified as estrogen receptor-positive $\left(\mathrm{ER}^{+}\right)$. Estrogen exerts its effect in almost all cells and tissues in the body, particularly in the breast, the female reproductive tract, and other tissues such as the bone, adipose tissue, skin, hair, brain, skeletal muscle and the cardiovascular system (2). Estrogen receptors are activated by the highly potent endogenous estrogen, $17 \beta$-estradiol, a natural ER ligand (3, 4). The binding of $17 \beta$-estradiol to ER is highly specific and occurs in a conformationally specific manner (5). Furthermore, it has been found that the ER is able to bind to other compounds that share similar structural features with $17 \beta$-estradiol (5). This structural analogy with $17 \beta$-estradiol may be useful, particularly when determining the estrogenicity of a particular chemical (6). The primary treatment option for estrogen-responsive breast cancers is anti-estrogen therapy, such as Tamoxifen or aromatase inhibitors (7). Although the majority of patients initially benefit from treatment with tamoxifen, $40 \%$ of all metastatic breast cancer patients who receive tamoxifen therapy eventually acquire resistance towards this therapeutic compound (8). Unfortunately, long-term treatment with tamoxifen has also been linked to an increased risk of endometrial cancer $(9,10)$.

To date, novel cytotoxic agents developed with unique mechanisms of action have not been therapeutically suitable for the treatment of cancer, since many of these compounds lack tumour selectivity (11). Generally, patients with endocrine-related cancers are at increased risk of developing osteoporosis as a complication of chemotherapy (12). Consequently, the adverse effects and the inefficacies of most chemotherapeutic therapies have motivated extensive investigations of alternatives (13). Multi-target combination drug therapies have, thus, been recognized as the current trend in drug design and discovery, the efficacy of which depends 
on the biological target, as well as the molecular pathway concomitantly affected by the drug component(s) $(14,15)$.

Curcumin, derived from turmeric, is a well-characterised chemopreventative compound and has established its anticancer effects in numerous cancer cell lines and animal models (16). Besides being used as an adjuvant in breast cancer chemotherapy, curcumin is able to regulate many signalling targets and has been used to augment targeted therapy sensitization (17). The therapeutic benefit of curcumin as a clinical drug, however, remains a challenge due to its poor bioavailability $(18,19)$. Various concerns have been raised regarding the efficacy of curcumin against cancer (20-22). A recent review concluded that curcumin does not possess the properties of a good drug candidate, and that the clinical potential of this compound should be dismissed due to the lack of evidence of its therapeutic effects in various clinical trials (20). In contrast, it has been argued that several randomized, double-blind, placebocontrolled clinical trials involving curcumin yielded promising results, and that the molecular targets of curcumin, including their regulatory mechanisms, does indeed warrant further investigation (23).

In view of these considerations, it is important to note the positive effect of curcumin as an adjuvant to current chemotherapies; for instance, it was found that curcumin increases the sensitivity of various cancer cell lines to tamoxifen (14), as well as cisplatin and doxorubicin (24). Moreover, studies investigating the therapeutic effects of curcumin against rheumatoid arthritis (25) and chronic obstructive pulmonary disease (26), including studies based on an experimental cerebral malaria model in mice (27) indicate that curcumin may offer significant promise as a therapeutic agent.

The compounds used in this study (Figure 1) are novel, synthetically-derived polycyclic aromatic hydrocarbons, belonging to the aminonaphthoquinone class of compounds (coded Rau 008, Rau 010, Rau 015 and Rau 018). Aminonaphthoquinones have shown potential as anti-cancer agents $(28,29)$. In particular, the cytotoxicity of Rau 010 and Rau 018 was assayed against cervical carcinoma (HeLa) and T-cell leukaemia (Jurkat) cells and it was found that these aminonaphthoquinones showed significant anti-proliferative activity against both cell lines (29). Furthermore, the Rau compounds were screened for cytotoxicity against MCF-7 breast cancer cells as well as freshly-isolated white blood cells, the latter representative of the 'normal' cell. Results showed that all the compounds were significantly cytotoxic towards the breast cancer cells, while Rau 010 was the only compound that did not appear to be cytotoxic towards white blood cells (30).

The evaluation of drug-drug interactions is important in all areas of medicine. This study was, thus, aimed at determining whether various combinations of curcumin and the Rau compounds were able to exert synergistic anti-<smiles>[R10]OCCOC</smiles><smiles>[R]O[R4]O[Na]</smiles><smiles>[R10][R19]</smiles><smiles>[R10][R4]O[Na]</smiles>

Figure 1. The code names and structures of the aminonapthoquinones used in the anticancer analyses.

estrogenic effects on ER ${ }^{+}$MCF-7 breast cancer cells, using the combination index method (31). This was followed by determining whether the relevant combinations exhibited potential synergistic anti-proliferative effects against the ER $^{-}$MDA-MB-231 breast cancer cell line, as well as the HEC-1A (endometrial carcinoma) and MG-63 (osteosarcoma) cell lines. The endometrial cancer and osteosarcoma cell lines were included to determine whether the drug combinations were capable of displaying similar effects on other estrogenresponsive tissues in addition to mammary tissue. To investigate the potential anti-estrogenic effects of the relative test agents (alone and in combination with curcumin), we examined: i) the effect on cell proliferation using the E-screen assay, ii) the ability to induce the Insulin Growth Factor Binding Protein-3 (IGFBP-3), a known anti-estrogenic marker in MCF-7 cells (32), (iii) the effect on alkaline phosphatase activity (ALP) and osteocalcin levels, two wellknown markers for osteoblastic differentiation and mineralization (33), iv) the effect on ALP activity in HEC-1A cells, a known marker of estrogen-responsiveness in endometrial cancer cells $(34,35)$.

\section{Materials and Methods}

Cell culture and maintenance. Cells were routinely maintained as monolayer cultures in 25 or $75 \mathrm{~cm}^{2}$ cell culture flasks (Nest Biotechnology, Wuxi, China) in Dulbecco's Minimal Essential Medium (DMEM) (Hyclone Ltd., Northumberland, UK) supplemented with $10 \%$ foetal bovine serum (Hyclone Ltd.). The cell lines were maintained between $1 \times 10^{5}$ and $1 \times 10^{7}$ cells $/ \mathrm{mL}$ at $37^{\circ} \mathrm{C}$ in a humidified atmosphere with $5 \% \mathrm{CO}_{2}$ and $95 \%$ air. The cell lines (MCF-7, MDA-MB-231, MG-63 and HEC-1A) were obtained from the National Institute of Biomedical Innovation (Osaka, Japan). 
Table I. Combination Index (CI) values of the different combinations in the MCF-7 cell line.

\begin{tabular}{|c|c|c|c|c|c|c|c|c|}
\hline \multirow{2}{*}{$\begin{array}{l}\text { Rau/control } \\
(\mu \mathrm{M})\end{array}$} & \multirow{2}{*}{$\begin{array}{l}\text { Curcumin } \\
\quad(\mu \mathrm{M})\end{array}$} & \multirow{2}{*}{$\begin{array}{l}\text { Combination } \\
\text { ratio }(\%)\end{array}$} & \multicolumn{6}{|c|}{$\mathrm{CI}$} \\
\hline & & & Rau 008 & Rau 010 & Rau 015 & Rau 018 & Tamoxifen & $17 \beta$-estradiol \\
\hline 150 & 0 & 100:0 & 1 & 1 & $1 \pm 0$ & $1 \pm 0$ & $1 \pm 0$ & $1 \pm 0$ \\
\hline 135 & 12.5 & $90: 10$ & $1.16 \pm 0.12$ & $2.13 \pm 0.43$ & $1.08 \pm 0.12$ & $1.06 \pm 0.04$ & $1.25 \pm 0.01$ & $2.21 \pm 0.98$ \\
\hline 120 & 25 & $80: 20$ & $1.01 \pm 0.43$ & $1.83 \pm 0.79$ & $1.02 \pm 0.12$ & $1.71 \pm 0.34$ & $2.04 \pm 1.00$ & $2.09 \pm 0.17$ \\
\hline 105 & 37.5 & $70: 30$ & $1.44 \pm 0.52$ & $1.20 \pm 0.09$ & $0.90 \pm 0.07$ & $2.46 \pm 0.54$ & $2.71 \pm 0.84$ & $3.83 \pm 0.40$ \\
\hline 90 & 50 & $60: 40$ & $1.72 \pm 0.37$ & $1.80 \pm 0.50$ & $0.93 \pm 0.11$ & $2.23 \pm 0.41$ & $>10$ & $1.58 \pm 0.18$ \\
\hline 75 & 62.5 & $50: 50$ & $1.69 \pm 0.51$ & $1.42 \pm 0.22$ & $1.58 \pm 0.22$ & $2.16 \pm 0.03$ & $>10$ & $2.04 \pm 0.05$ \\
\hline 60 & 75 & $40: 60$ & $1.88 \pm 0.46$ & $>10$ & $1.37 \pm 0.04$ & $2.20 \pm 0.45$ & $1.16 \pm 0.42$ & $2.99 \pm 0.74$ \\
\hline 45 & 87.5 & $30: 70$ & $1.77 \pm 0.10$ & $2.20 \pm 0.56$ & $1.37 \pm 0.27$ & $1.17 \pm 0.01$ & $1.32 \pm 0.03$ & $3.38 \pm 0.46$ \\
\hline 30 & 100 & $20: 80$ & $1.86 \pm 0.04$ & $1.94 \pm 0.61$ & $1.14 \pm 0.07$ & $1.26 \pm 0.26$ & $1.51 \pm 0.06$ & $1.23 \pm 0.14$ \\
\hline 15 & 112.5 & $10: 90$ & $1.49 \pm 0.06$ & $1.50 \pm 0.41$ & $0.89 \pm 0.08$ & $2.17 \pm 0.06$ & $3.25 \pm 0.58$ & $>10$ \\
\hline 0 & 125 & $0: 100$ & 1 & 1 & $1 \pm 0$ & $1 \pm 0$ & $1 \pm 0$ & $1 \pm 0$ \\
\hline
\end{tabular}

Combination index $(\mathrm{CI})$ was defined as follows: $\mathrm{CI}=\mathrm{C}_{\mathrm{A}, \mathrm{x}} / \mathrm{IC} \mathrm{x}_{\mathrm{x}} \mathrm{A}+\mathrm{C}_{\mathrm{B}, \mathrm{x}} / \mathrm{IC}_{\mathrm{x}, \mathrm{B}}$. A CI value less than 1 represents antagonism, a $\mathrm{CI}$ value greater than 1 represents synergism and a $\mathrm{CI}$ value equal to 1 represents additivity.

Preparation of compounds and controls. The Rau compounds were prepared according to a previously reported method (29). The spectroscopic properties of Rau 008 (36), Rau 010 (29), Rau 015 (37) and Rau 018 (29) have been reported previously. Stock solutions of the Rau compounds, curcumin (Sigma-Aldrich, Munich, Germany) and Tamoxifen (Sigma-Aldrich) were initially dissolved in $100 \%$ dimethyl sulfoxide (DMSO) to a stock concentration of $100 \mathrm{mM}$, before dilution to working concentrations in cell culture media. 17ß-Estradiol (Sigma-Aldrich) was prepared similarly using absolute ethanol. Dilutions (at final well concentrations ranging between $0.4-150 \mu \mathrm{M}$ ) were prepared on the day of the experiment from stock solutions with phenol red-free DMEM (Sigma-Aldrich), supplemented with $2 \%$ charcoal-dextran-treated foetal calf serum (FCS) (Sigma-Aldrich). The final well concentration of DMSO or ethanol in the control or treated samples was $0.15 \%(\mathrm{v} / \mathrm{v})$.

Estrogenicity analysis. The E-screen was performed as previously described (38), with slight modifications. Cells were seeded at $1 \times 10^{4}$ cells per well in complete growth medium in 96-well tissue culture plates. Once confluence was reached, the growth media was replaced by phenol red-free DMEM supplemented with $2 \%$ charcoal-dextran-treated FCS. The cells were estrogen-starved for $72 \mathrm{~h}$ at $37^{\circ} \mathrm{C}$. This was followed by treating the cells with fresh estrogen-free medium containing the various test compounds and controls (curcumin, tamoxifen, 17 $\beta$-estradiol) at final well concentrations ranging between 0.4 and $150 \mu \mathrm{M}$. In addition, one row of cells received vehicle $(0.15 \%$ DMSO or $0.15 \%$ ethanol) alone, whereas another row was left untreated. The cells were incubated for $24 \mathrm{~h}$ at $37^{\circ} \mathrm{C}$, after which the conditioned culture medium was removed and stored at $-80^{\circ} \mathrm{C}$ for IGFBP-3 determination. Subsequently, the 3-(4,5-dimethylthiazol-2-yl)-2,5diphenyltetrazolium bromide (MTT) assay was performed as described (39) with minor modifications. Cells were incubated with $100 \mu \mathrm{l}$ of MTT $(0.5 \mathrm{mg} / \mathrm{ml}$; Duchefa Biochemic, Haarlem, Netherlands) for $3 \mathrm{~h}$ at $37^{\circ} \mathrm{C}$. The purple formazan crystals formed were solubilized in $100 \%$ DMSO $(200 \mu \mathrm{l})$ and the absorbance read at $540 \mathrm{~nm}$ using a microtiter plate reader (Bio-Tek Instruments Inc.,
Winooski, VT, USA), against a DMSO blank. The percentage proliferation was expressed as a percentage of the $0.15 \%$ DMSO or ethanol (for 17 $\beta$-estradiol) vehicle controls.

Combination studies. A dose-response study was first completed to determine the $50 \%$ inhibitory concentration $\left(\mathrm{IC}_{50}\right)$ of the individual drugs, followed by $\mathrm{IC}_{50}$ calculation for the various drug combinations with curcumin using the E-screen assay. This entailed treating estrogen starved-cells (for $24 \mathrm{~h}$ ) with increasing final well concentrations of curcumin $(0.39-125 \mu \mathrm{M})$, Tamoxifen $(0.47-150$ $\mu \mathrm{M}), 17 \beta$-estradiol $(0.47-150 \mu \mathrm{M})$ and the Rau compounds $(0.47$ $150 \mu \mathrm{M}$ ), whilst for the combination assay, the combination ratio of each of the two drugs (Rau/controls and curcumin) were prepared as shown in Table I. The effect of the compounds on cell proliferation was assessed via the MTT assay $(n=3)$ and drug response curves were generated using GraphPad Prism v6.0 (GraphPad Software Inc., San Diego, CA, USA). Thereafter, the combination index (CI) equation $(31,40)$ was used to analyse the potential interactions (synergistic, additive or antagonistic) of the various drug combinations. The $\mathrm{CI}$ is an algebraic representation of the extent of a drug interaction at a certain dose-effect level $(31,41$, 42), using the equation: $\mathrm{CI}=\mathrm{C}_{\mathrm{A}, \mathrm{x}} / \mathrm{IC}_{\mathrm{x}, \mathrm{A}}+\mathrm{C}_{\mathrm{B}, \mathrm{x}} / \mathrm{IC}_{\mathrm{x}, \mathrm{B}}(40,41)-$ where $C_{A}, x$ and $C_{B, x}$ are the concentrations of drug $A$ and drug $B$ used in the combination to produce an effect $\mathrm{x}$, and are normalized by their corresponding concentrations used to produce the same effect as an individual agent, $\mathrm{IC}_{\mathrm{x}, \mathrm{A}}$ and $\mathrm{IC}_{\mathrm{x}, \mathrm{B}}$, respectively. A CI of less than, equal to, and more than 1 indicates synergy, additivity, and antagonism, respectively $(31,40)$.

Insulin-like growth factor binding protein 3 determinations. Following estrogenicity analysis of the compounds, conditioned media of treated cells (MCF-7 and MDA-MB-231) and the controls were collected and centrifuged at $10,000 \times g$ for $5 \mathrm{~min}$ and stored at $-80^{\circ} \mathrm{C}$. The concentration of the IGFBP- 3 expressed was measured using the RayBio ${ }^{\circledR}$ Human IGFBP-3 ELISA kit (ELH-IGFBP3-00, Norcross, GA, USA) according to the manufacturer's instructions. 
Mineralization assay. The mineralization assay for MG-63 cells was carried out as previously described (43). The differentiating medium was refreshed every 3-4 days for 21 days in total, followed by alkaline phosphatase and osteocalcin determinations.

Determination of alkaline phosphatase activity. ALP activity was determined in mineralised MG-63 and HEC-1A culture supernatants. HEC-1A cells were treated as described for the Escreen assay and the medium (containing the individual and combined treatments) was refreshed every 3 days for 10 days in total (34), after which the ALP activity in the culture supernatant was analysed (44). The ALP activity in each sample was normalized to the cell protein content, as measured by the bicinchoninic assay (Pierce BCA kit, catalogue number 23227, Rockford, IL, USA). ALP activity is expressed as $\mu \mathrm{mol} \mathrm{QNP}$ formed $/ \mathrm{min} / \mathrm{mg}$ protein.

Osteocalcin determination. MG-63 culture supernatants were obtained following the mineralization assay and the amount of osteocalcin present was determined using the GenWay hOSTEASIA Kit (catalogue number: 40-056-205017, San Diego, CA, USA) according to the manufacturer's instructions.

Statistical analysis. Statistical dose-response regression analyses were carried out by applying a best-fit approach. Analysis of doseresponse curves and determination of $\mathrm{IC}_{50}$ values were obtained using GraphPad Prism v6.0 software (GraphPad Software Inc., San Diego, CA, USA). All data are reported as mean \pm SD for triplicate experiments. Non-parametric grouping of data was analysed by ANOVA and secondary data analysis for significance with Student's $t$-test. Values of $p<0.05$ were considered significant.

\section{Results}

Combination studies. To fully evaluate the combination effects of curcumin and the test compounds in the MCF-7 breast cancer cell line, drug interactions were analyzed using the CI method as described previously $(31,40)$. Cells were treated with various concentrations of the relevant test compound alone and in combination with curcumin, using the E-screen assay. Dose-effect curves for the single compounds and the selected drug combinations were constructed from which the relevant $\mathrm{IC}_{50}$ values were determined, followed by determination of the CI for each drug interaction (Table I). Combination index analysis of the Rau 008:curcumin combination in MCF-7 cells was inconclusive as the CI values ranged between $1.01 \pm 0.43$ and $1.88 \pm 0.46$. The $80: 20$ Rau 008:curcumin combination ratio was selected, since the CI for this drug interaction was $1.01 \pm 0.43$, indicating a possible additive/synergistic interaction. Most of the Rau 010:curcumin interactions appeared to be antagonistic in MCF-7 cells, where the 80:20 Rau 010:curcumin combination ratio $(\mathrm{CI}=1.83 \pm 0.79)$ was selected for further analyses since the $\mathrm{CI}$ value was close to 1. Combination index evaluation of the Rau 015:curcumin combination showed that three combinations resulted in synergism, with CI values of $0.90 \pm 0.07 ; 0.93 \pm 0.11$ and $0.89 \pm 0.08$ for the 70:30, 60:40 and 10:90 Rau 015:curcumin ratios, respectively. The 10:90 Rau 015:curcumin combination ratio was selected for further analyses, since the $\mathrm{CI}$ for this drug interaction $(0.89 \pm 0.08)$ indicates a possible synergistic drug interaction. Combination index determination of the Rau 018:curcumin combination revealed mostly antagonistic interactions, with few potential additive interactions, but no synergistic drug interactions. The 20:80 Rau 018:curcumin combination ratio was chosen for further analyses, since this drug interaction could potentially be additive $(\mathrm{CI}=1.26 \pm 0.26)$.

The tamoxifen plus curcumin interaction indicated many antagonistic, few potentially additive but no synergistic drug interactions. The 40:60 tamoxifen:curcumin combination ratio was chosen since this drug interaction indicated potential synergy based on its $C I$ value of $1.16 \pm 0.42$. Combination index evaluation of the $17 \beta$-estradiol:curcumin combination indicated mostly antagonistic drug interactions, except for the 20:80 17 $\beta$ estradiol:curcumin combination ratio $(\mathrm{CI}=1.23 \pm 0.14)$, which suggests a potential additive interaction, therefore this combination was selected for further analyses.

Subsequently, drug combinations displaying potential synergistic or additive interactions in the MCF-7 cell line were selected to determine the combination effects of the compounds and curcumin in the MDA-MB-231, MG-63 and HEC-1A cell lines respectively. Notably, the Rau 015:curcumin combination indicated a potential additive drug interaction in MDA-MB-231 cells $(\mathrm{CI}=1.14 \pm 0.09)$, while the rest of the selected drug combinations yielded antagonistic effects in these cells $(C I>1)$. In MG-63 cells, all the drug interactions were antagonistic $(\mathrm{CI}>1)$. In HEC-1A cells, Rau 008:curcumin $\quad(\mathrm{CI}=0.52 \pm 0.12), \quad$ Rau 010:curcumin $(\mathrm{CI}=0.62 \pm 0.16)$ and tamoxifen:curcumin $(\mathrm{CI}=0.75 \pm 0.04)$ yielded synergistic effects, whereas the rest of the drug combinations indicated antagonistic effects $(\mathrm{CI}>1)$.

Estrogenicity analyses. The E-screen assay is useful in determining the estrogenic effect of a particular compound on cell proliferation in ER-competent systems, particularly in $\mathrm{ER}^{+}$human breast cancers (38). Estrogenicity analyses in MCF-7 cells using the E-screen assay (Figure 2) indicate that combinations of Rau 015, Rau 018, Tamoxifen and 17 $\beta$ estradiol with curcumin exerted significant anti-proliferative effects compared to individual treatment $(p<0.05$,

Figure 2. Effect on cell proliferation in the different tumour cell lines. Experimental details are presented in the Materials and Methods section. The proliferation of the cells treated with the 0.15\% DMSO or ethanol vehicle control was not significantly different in relation to the untreated control $(p>0.05)$, and for this reason, the cell proliferation of the vehicle controls was set at 100\% (not shown). The estrogenic/antiestrogenic effect on cell proliferation is presented as a percentage of the vehicle control and is reported as mean $\pm S . D$. values $(n=3)$, where ${ }^{*} p<0.05$ relative to the relevant vehicle control; ${ }^{*} p<0.05$ relative to $17 \beta$-estradiol and ${ }^{\circ} p<0.05$ relative to individual treatment. 

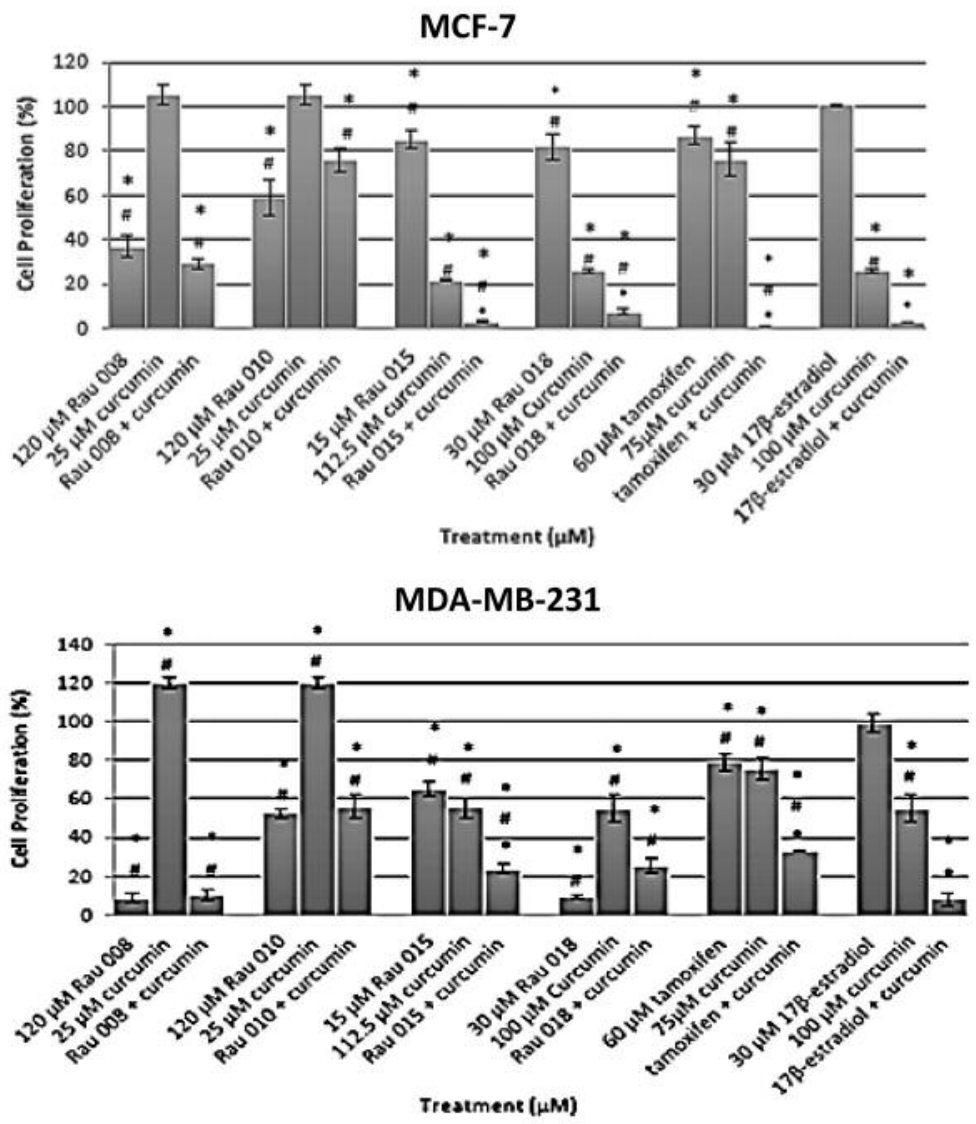

MG-63
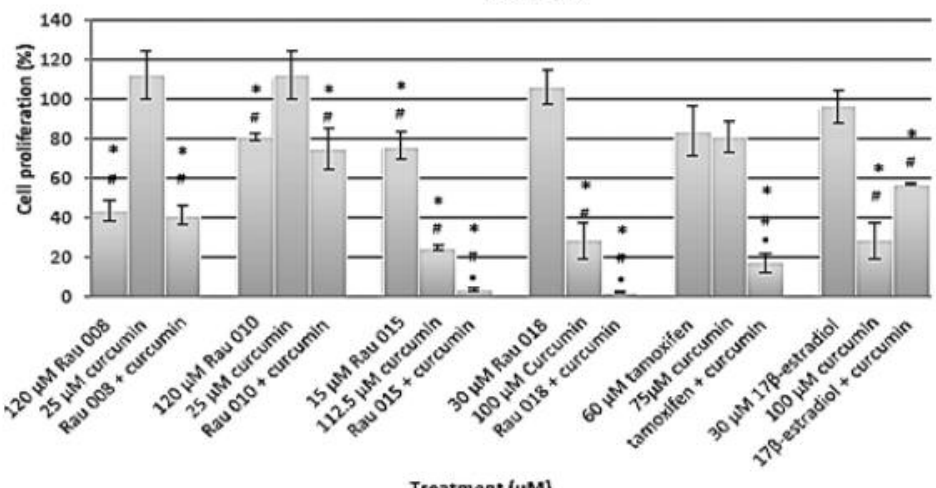

Treatment ( $\mu \mathrm{M})$

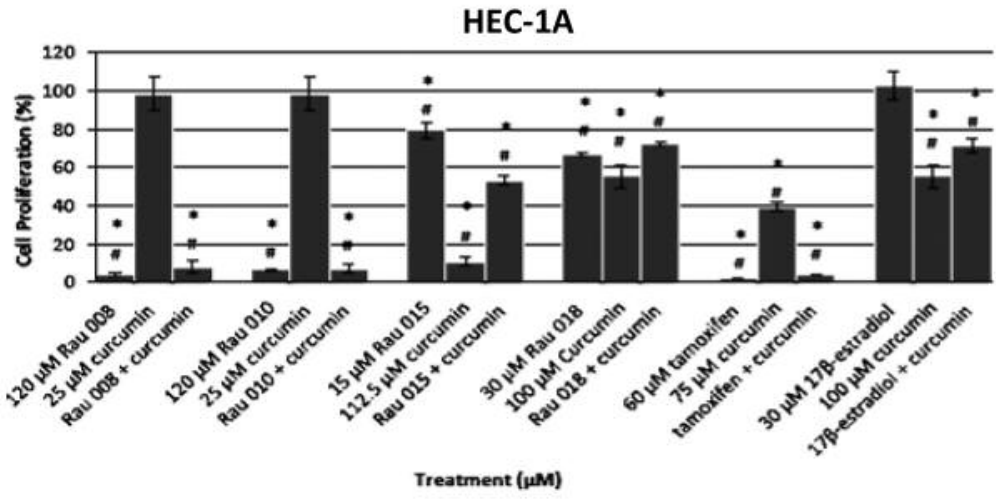


respectively). The anti-proliferative effect exerted by these combinations in the MCF-7 cells was also significantly marked compared to the effect exerted by $17 \beta$-estradiol alone $(p<0.05)$. The MDA-MB-231 cell line served as a negative control in determining the potential of the compounds as antiestrogenic agents. As indicated in Figure 2, all the test agents (except $25 \mu \mathrm{M}$ curcumin) significantly reduced MDA-MB231 cell proliferation compared to the relevant controls $(p<0.05)$, whilst combinations of Rau 015 , tamoxifen or $17 \beta-$ estradiol with curcumin appeared significantly more effective than individual treatment at inhibiting cell proliferation $(p<0.05)$. In MG-63 cells (Figure 2), combinations of Rau 015 , Rau 018 and tamoxifen with curcumin significantly reduced cell proliferation compared to individual treatment $(p<0.05$ respectively $)$ and these anti-proliferative effects were more marked than that of the other test agents or $17 \beta$ estradiol $(p<0.05)$. In HEC-1 A cells (Figure 2), combinations of Rau 008, Rau 010 and Tamoxifen with curcumin exerted a significant inhibitory effect on cell proliferation compared to $17 \beta$-estradiol $(p<0.05)$; however, the anti-proliferative effect of these combinations appeared to be similar to that of individual treatment $(p<0.05)$.

Influence of selected combinations on IGFBP-3 levels. A strong negative correlation exists between IGFBP-3 levels and MCF-7 cell proliferation (32). In MCF-7 cells (Figure 3 ), the effect of $17 \beta$-estradiol (alone) on IGFBP-3 levels correlates negatively with MCF-7 cell proliferation (Figure 2). Moreover, a negative correlation is noted particularly after treatment with Rau 008+curcumin, Rau 018+curcumin, tamoxifen+curcumin and $17 \beta$-estradiol+curcumin, where a significant increase in IGFBP-3 accumulation in the relevant cell culture supernatants (Figure 3) is associated with reduced MCF-7 cell proliferation (Figure 2).

Given that IGFBP-3 is a marker for anti-estrogenicity in $\mathrm{ER}^{+}$breast cancer cells, in this study, the $\mathrm{ER}^{-} \mathrm{MDA}-\mathrm{MB}-$ 231 cell line was representative of a negative control for ERdependent IGFBP-3 activity. Although all the test compounds (with the exception of $25 \mu \mathrm{M}$ curcumin and $30 \mu \mathrm{M} 17 \beta$-estradiol) significantly reduced IGFBP-3 levels in MDA-MB-231 cells (Figure 3), the high proliferation rate of MDA-MB-231 cells treated with $17 \beta$-estradiol (Figure 2) in the presence of high levels of IGFBP-3 (Figure 3) appears contradictory compared to the action of IGFBP-3 on MCF-7 cells reported in this study. Accordingly, a negative correlation between IGFBP-3 levels and cell proliferation in $\mathrm{ER}^{-}$breast cancer cells is not expected.

Influence of selected combinations on ALP activity in HEC-1A cells. The activity of ALP in reproductive tissue can also potentially be used as a tool in explaining the mechanism of hormonal control, particularly in endometrial carcinomas (45). To determine the response of HEC-1A endometrial cancer cells to various treatments with the selected drugs and their relative combinations with curcumin, ALP activity was measured in HEC-1A culture supernatants and these effects are illustrated in Figure 4. Notably, only the Rau 008+curcumin, Rau $015+$ curcumin and $17 \beta$-estradiol+ curcumin combinations inhibited the activity of ALP (Figure 4) and correlated with reduced HEC-1A proliferation (Figure 2), while the antiproliferative effect exerted by the remaining test agents does not appear to affect the activity of ALP.

Influence of selected combinations on the induction of osteogenic differentiation and mineralization of $M G-63$ cells. Osteosarcoma-derived MG-63 cells are believed to display similar features to that of the undifferentiated early osteoblast phenotype (46). The osteoblastic response to external stimuli (such as drugs or hormones etc.) is commonly assessed using in vitro osteogenesis assays (47) that typically involves growing the cells to confluency, followed by the addition of specific osteogenic medium to promote matrix maturation and mineralization. Thereafter, cell differentiation is usually assessed by examining certain markers for osteoblastic differentiation and mineralization, such as ALP activity and osteocalcin levels $(33,47,48)$.

To determine the effect of the selected combinations on the induction of osteogenic differentiation and mineralisation of MG-63 cells (Figure 5), ALP activity and osteocalcin levels were determined. Rau 010+curcumin and Rau $015+$ curcumin were associated with a significant increase in ALP activity $(p<0.05)$, whilst combinations of Rau 008, Rau 018, tamoxifen and 17 $\beta$-estradiol with curcumin did not significantly affect osteoblast differentiation $(p>0.05)$, due to their inability to affect the activity of ALP in the MG-63 cells. All the drug combinations (except Rau 18+curcumin) significantly reduced osteocalcin secretion $(p<0.05)$, and may therefore exert a negative effect on osteoblast mineralization; whereas the Rau 018+curcumin combination appears not to significantly affect bone differentiation or mineralisation.

\section{Discussion}

In this study, synthetic aminonaphthoquinone derivatives were tested individually and in combination with curcumin regarding their potential as anti-estrogenic agents in $\mathrm{ER}^{+}$ MCF-7 breast cancer cells. Selected combination treatments were then applied to $\mathrm{ER}^{-}$MDA-MB-231 breast cancer cells, as well as in other estrogen-responsive tumour cell lines (MG-63 and HEC-1A) to determine their potential as antibreast cancer agents.

Notably, the CI of Rau $015(15 \mu \mathrm{M})$ and curcumin $(112.5 \mu \mathrm{M})$ indicated synergy in the MCF-7 cell line (Table I). None of the Rau:curcumin combinations displayed synergy in MDA-MB-231 or MG-63 cells, whilst 

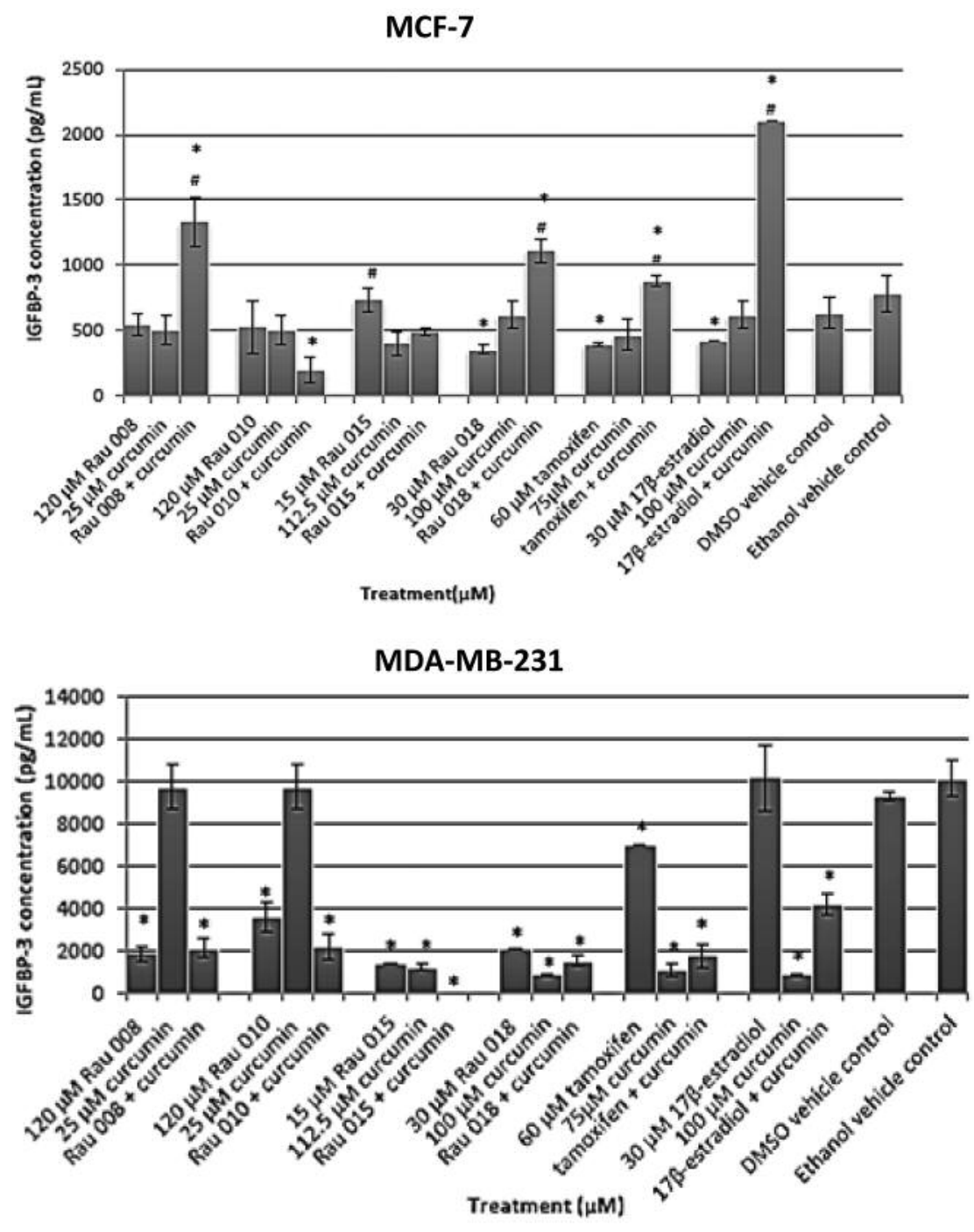

Figure 3. Effect of the compounds and selected combinations on IGFBP-3 levels in breast cancer cells. IGFBP-3 levels are presented as the amount of IGFBP-3 secreted per cell population in each well $(\mathrm{pg} / \mathrm{ml})$ and is reported as mean $\pm S . D$. values $(n=3)$, where $* p<0.05$ relative to the relevant vehicle control and ${ }^{\#} p<0.05$ relative to $17 \beta$-estradiol.

combinations of Rau $008(120 \mu \mathrm{M})$ and curcumin $(25 \mu \mathrm{M})$, as well as $\operatorname{Rau} 010(120 \mu \mathrm{M})$ and curcumin $(25 \mu \mathrm{M})$, indicated synergism in HEC-1A cells.

Anti-estrogenicity analysis indicated good compatibility of $15 \mu \mathrm{M}$ Rau $015+112.5 \mu \mathrm{M}$ curcumin, $30 \mu \mathrm{M}$ Rau 018+100 $\mu \mathrm{M}$ curcumin, $60 \mu \mathrm{M}$ tamoxifen $+75 \mu \mathrm{M}$ curcumin and $30 \mu \mathrm{M} 17 \beta$-estradiol $+100 \mu \mathrm{M}$ curcumin in $\mathrm{ER}^{+}$breast cancer (Figure 2). Nonetheless, all the selected drug combinations appeared to exert anti-cancer effects. For instance, a combination of Rau $008(120 \mu \mathrm{M})$ and curcumin $(25 \mu \mathrm{M})$ exerted an anti-estrogenic effect in $\mathrm{ER}^{+}$breast cancer (Figure 2), including osteosarcoma (Figure 2) and endometrial cancer (Figure 2), and the anti-proliferative effect of this combination in $\mathrm{ER}^{+}$breast cancer cells was associated with increased IGFBP-3 levels (Figure 3). Further, the inhibitory effect of the Rau 008+curcumin combination on osteocalcin levels (Figure 5) and endometrial ALP activity (Figure 4) may be anti-estrogenic. The antiproliferative effect exerted by Rau 008+curcumin in MCF-7 and MDA-MB-231 cells (Figure 2) indicates that the mechanism of action of this particular combination may differ in $\mathrm{ER}^{+}$and $\mathrm{ER}^{-}$breast cancer.

Rau $010(120 \mu \mathrm{M})$ and curcumin $(25 \mu \mathrm{M})$ exerted an anti-proliferative effect in all the respective cell lines (Figure 2); and was associated with increased ALP levels and reduced osteocalcin levels in MG-63 cells (Figure 5). 


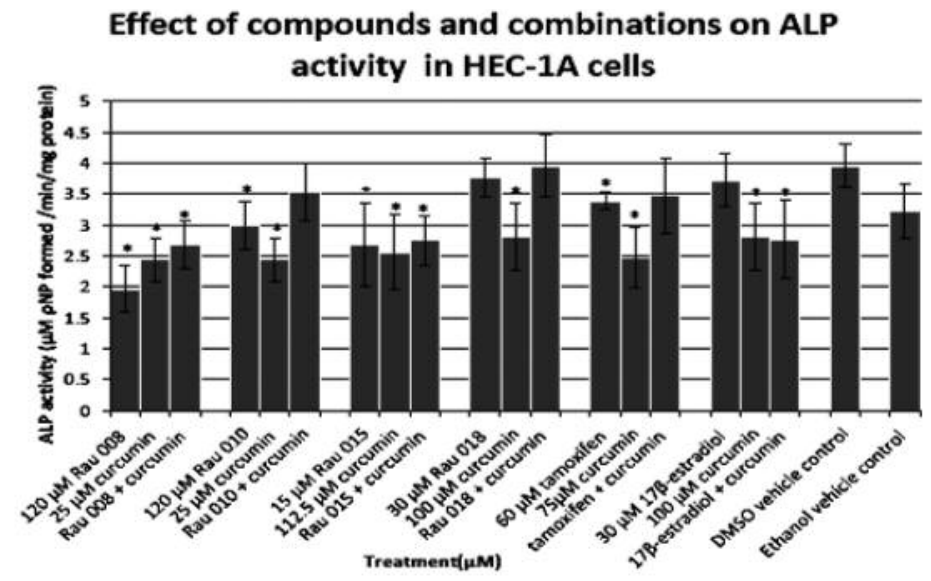

Figure 4. Effect of the compounds and selected combinations on alkaline phosphatase activity in HEC-1A endometrial cancer cells. All experiments were carried out in phenol red-free DMEM + 2\% charcoal-stripped FCS, which was replaced every 3 days. The cells were harvested on the 10th day in culture and ALP activity was determined. Data is reported as the mean $\pm S . D$. values $(n=3)$. Statistical significance is indicated as $* p<0.05$ in relation to the relevant vehicle control.

These findings suggest that this combination stimulates osteoblast differentiation, but exerts a negative effect on bone mineralization.

Rau $015(15 \mu \mathrm{M})$ and curcumin $(112.5 \mu \mathrm{M})$ reduced the proliferation of both $\mathrm{ER}^{+}$and $\mathrm{ER}^{-}$breast cancers (Figure 2), including osteosarcoma (Figure 2) and endometrial cancer cells (Figure 2). This anti-proliferative effect was associated with increased ALP activity and reduced osteocalcin levels in osteoblastic MG-63 cells (Figure 5), indicating that Rau $015+$ curcumin could exert a negative effect on osteoblast mineralization. Furthermore, the anti-proliferative effect of this particular combination in HEC-1A cells (Figure 2) was also associated with reduced ALP activity in these cells (Figure 4). Nonetheless, the lack of a significant response by MCF-7 cells on IGFBP-3 levels after treatment with Rau $015+$ curcumin (Figure 3 ) indicates that the anti-proliferative effect of this combination may not be ER-mediated.

The Rau $018 \quad(30 \mu \mathrm{M})$ and curcumin $(100 \mu \mathrm{M})$ combination significantly reduced the proliferation of MCF7, MDA-MB-231, MG-63 and HEC-1A cells (Figure 2), where this effect was significantly more enhanced in the MCF-7 and MG-63 cell lines compared to that of individual treatment in these cells. In MCF-7 cells (Figure 3), IGFBP3 levels were significantly increased, indicating that the antiproliferative effect of the Rau 018+curcumin combination in these cells may be anti-estrogenic. The inhibitory effect on MDA-MB-231 and HEC-1A cell proliferation (Figure 2), in addition to the lack of response by HEC-1A cells on ALP activity (Figure 4), indicate that this effect may be mediated via an ER-independent pathway. These findings suggest that Rau 018+curcumin is able to inhibit both ER-dependent and ER-independent mediated growth. Notably, it appears that the Rau 018+curcumin combination does not significantly affect bone differentiation or mineralization.

Interestingly, a combination of $60 \mu \mathrm{M}$ Tamoxifen and $75 \mu \mathrm{M}$ curcumin was found to synergistically inhibit the proliferation of MCF-7, MDA-MB-231, MG-63 and HEC$1 \mathrm{~A}$ cells (Figure 2). Considering that this effect was noted in MCF-7, MG-63 and HEC-1A cells and was associated with elevated IGFBP-3 levels in MCF-7 cells (Figure 3), it suggests that the anti-proliferative effect of this combination may be ER-mediated. Nonetheless, the inhibitory effect of the tamoxifen+curcumin combination was also marked in MDA-MB-231 cells (Figure 2), which indicates that this effect may be ER-independent. In view of these findings, it appears that the mechanism of action of this combination in ER-dependent and ER-independent tumours differs. Moreover, a combination of $30 \mu \mathrm{M} 17 \beta$-estradiol and 100 $\mu \mathrm{M}$ curcumin significantly reduced the proliferation of $\mathrm{MCF}$ 7, MDA-MB-231, MG-63 and HEC-1A cells (Figure 2); however, the anti-proliferative effect appeared more enhanced (compared to individual treatment) in the breast cancer cell lines. This effect appeared to be anti-estrogenic in MCF-7 cells due to the increased IGFBP-3 levels in these cells (Figure 3) and reduced osteocalcin levels in MG-63 cells (Figure 5). It appears that the anti-proliferative effect of this combination could be anti-estrogenic in the HEC-1A cells due to the reduced ALP activity (Figure 4), and may also be effective against $\mathrm{ER}^{-}$breast cancer.

Few studies have explored combinations of curcumin with endocrine therapy. This study showed that the antiproliferative effect of the tamoxifen+curcumin combination was more enhanced in breast cancer (MCF-7 and MDA-MB231), osteosarcoma and endometrial cancer-derived cells 

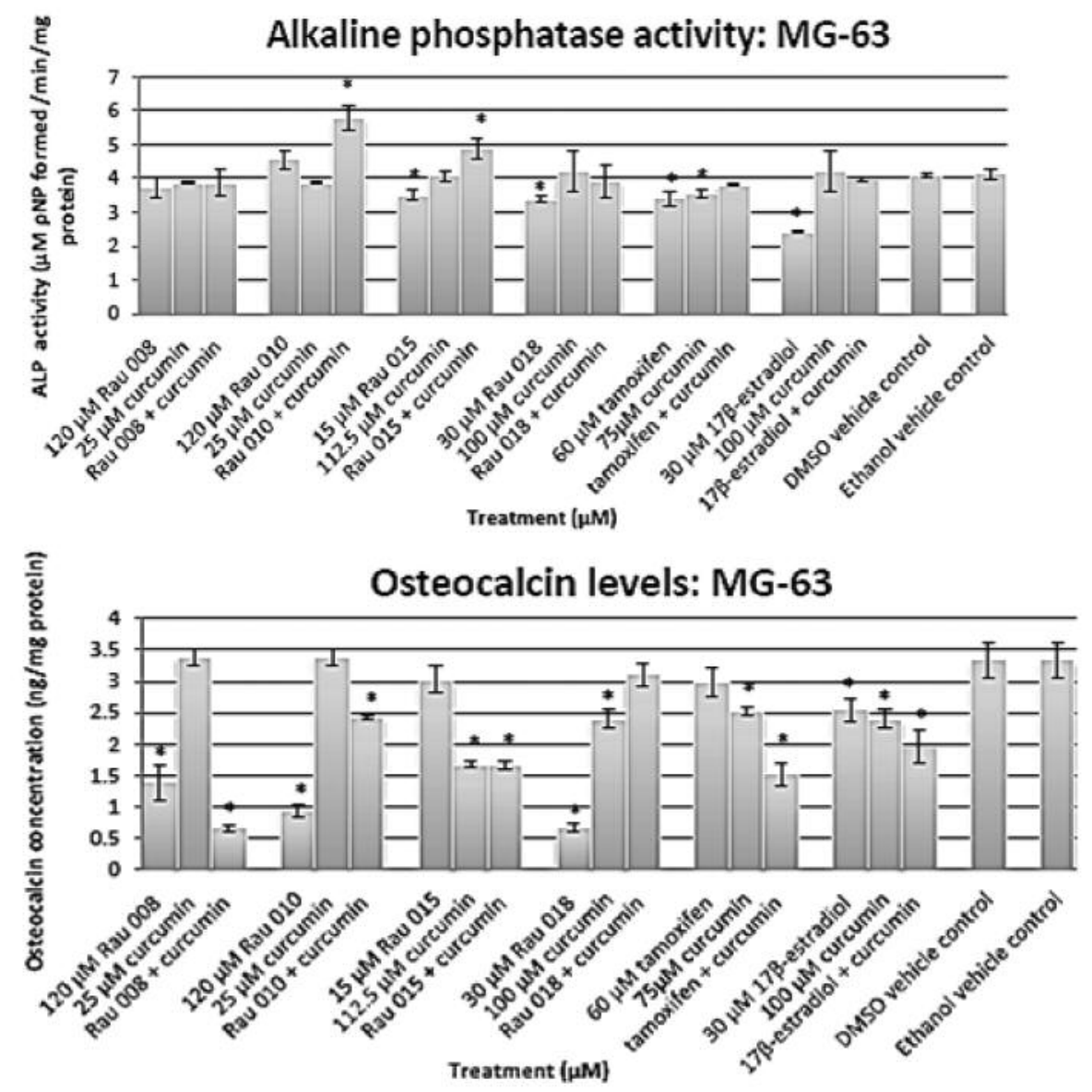

Figure 5. Effect of the compounds and selected combinations on ALP activity and osteocalcin secretion by MG-63 cells. Osteoblastic MG-63 cells were maintained for 21 days in differentiation medium. Cell culture supernatants were analyzed for ALP activity and osteocalcin levels. Results are reported as the mean $\pm S . D$. values $(n=3)$. Statistical significance is indicated as $* p<0.05$ in relation to the relevant vehicle control.

compared to individual treatment. These findings correlate with those from another study on tamoxifen-resistant breast cancer cells (14), where it was shown that a combination of 4-hydroxy-tamoxifen (concentration range $=0.5-8 \mu \mathrm{M}$ ) and curcumin $(2.5 \mu \mathrm{M})$ reduced cell proliferation significantly due to the ability of curcumin to modulate the response of these cells to Tamoxifen. Further, a combination study of curcumin $(50 \mu \mathrm{M})$ with exogenous $17 \beta$-estradiol $(10 \mathrm{nM})$ revealed that curcumin inhibited the stimulatory growth effect of $17 \beta$-estradiol on MCF-7 cells, and that the suppressive effect of curcumin in these cells was mediated by way of an ER-related pathway (49). These results are comparable with our finding that a combination of $17 \beta$ estradiol and curcumin induces a marked anti-proliferative effect in breast cancer-derived cells.

Our findings also show that curcumin enhanced the sensitivity of the tumour cells to the Rau compounds. For instance, a combination of Rau $015(15 \mu \mathrm{M})$ and curcumin
$(112.5 \mu \mathrm{M})$ resulted in a more enhanced anti-proliferative effect in both $\mathrm{ER}^{+}$and $\mathrm{ER}^{-}$breast cancer, as well as osteosarcoma cells compared to the effect of individual treatment. Moreover, the anti-proliferative effect of a combination of Rau 018 $(30 \mu \mathrm{M})$ and curcumin $(100 \mu \mathrm{M})$ was markedly more effective than individual treatment in $\mathrm{ER}^{+}$breast cancer and osteosarcoma-derived cells. Despite the potential of these combinations as anti-breast cancer agents, it is noteworthy that all the combinations (except Rau 018+curcumin) exerted a negative impact on bone mineralisation, which could ultimately be detrimental to bone health.

From this study it can be concluded that combinations of Rau $015(15 \mu \mathrm{M})$ and curcumin $(112.5 \mu \mathrm{M})$ or Rau 018 $(30 \mu \mathrm{M})$ and curcumin $(100 \mu \mathrm{M})$ may prove useful as potential therapeutic targets against breast cancer. Nonetheless, the most promising of these would be a combination of $30 \mu \mathrm{M}$ Rau 018 and $100 \mu \mathrm{M}$ curcumin, based on its ability to target both ER-dependent and ER- 
independent tumours without negatively affecting the bone mineralisation process. The results of this study provide a significant insight of the combinatorial effects of curcumin and synthetic aminonaphthoquinine derivatives against breast cancer and may offer a new approach to the treatment of breast cancer, particularly with a first- or second-line chemotherapy regimen. Nonetheless, before application in a clinical setting, further exploratory toxicity analyses should be conducted to determine any adverse effects exerted by the combination treatments. As this was a screening analysis for anticancer activity, future studies should also involve mechanistic studies. In this regard, it would be interesting to determine the cellular response initiated following treatment with the selected combinations and how this relates to cellular death and the apoptotic pathways.

\section{Acknowledgements}

This study was funded by the National Research Foundation, NRFThutuka Grant 87902, Pretoria, South Africa and the Nelson Mandela Metropolitan University, Port Elizabeth, South Africa. C. de Koning and W. van Otterlo gratefully acknowledge NRF research funding and the University of the Witwatersrand and Stellenbosch University for support.

\section{References}

1 Ferlay J, Soerjomataram I, Ervik M, Dikshit R, Eser S, Mathers C, Rebelo M, Parkin DM, Forman D and Bray F: Cancer Incidence and Mortality Worldwide: IARC CancerBase No. 11 [Internet]. Lyon, France: International Agency for Research on Cancer, GLOBOCAN 2012. 1(1), 2014.

2 Wend K, Wend P and Krum SA: Tissue-specific effects of loss of estrogen during menopause and aging: Review Article. Front Endocrinol 3(19): 1-14, 2012.

3 Dahlman-Wright $\mathrm{K}$, Cavailles $\mathrm{V}$ and Fuqua SA: International Union of Pharmacology. LXIV. Estrogen receptors. Pharmacol Rev 58(4): 773-781, 2006.

4 Farooq A: Structural and functional diversity of estrogen receptor ligands. Curr Top Med Chem 15(14): 1372-1384, 2015.

5 Nilsson S, Makela S, Treuter E, Tujague M, Thomsen J, Andersson G, Enmark E, Pettersson $\mathrm{K}$, Warner $\mathrm{M}$ and Gustafsson JA: Mechanisms of estrogen action. Physiol Rev 81: 1535-1565, 2001.

6 Shaw I and McCully S: A review of the potential impact of dietary endocrine disrupters on the consumer. Int J Food Sci Technol 37: 471-476, 2002.

7 Hayes EL and Lewis-Wambi JS: Mechanisms of endocrine resistance in breast cancer: an overview of the proposed roles of noncoding RNA. Breast Cancer Res 17: 40, 2015.

8 Musgrove EA and Sutherland RL: Biological determinants of endocrine resistance in breast cancer. Nat Rev Cancer 9: 631$643,2009$.

9 Vivacqua A, Bonofiglio D, Recchia AG, Musti AM, Picard D, Andò $S$ and Maggiolini $M$ : The $G$ protein-coupled receptor GPR30 mediates the proliferative effects induced by 17 betaestradiol and hydroxyl-Tamoxifen in endometrial cancer cells. Mol Endocrinol 20(3): 631-646, 2006.
10 Wickerham DL, Fisher B, Wolmark N, Bryant J, Costantino J, Bernstein L and Runowicz CD: Association of Tamoxifen and uterine sarcoma. J Clin Oncol 20: 2758-2760, 2002.

11 Chari RV: Targeted cancer therapy: conferring specificity to cytotoxic drugs. Acc Chem Res 41(1): 98-107, 2008.

12 Body JJ, Bergmann P, Boonen S, Boutsen Y, Devogelaer JP, Goemaere S, Reginster JY, Rozenberg S and Kaufman JM: Management of cancer treatment-induced bone loss in early breast and prostatic cancer - a consensus paper of the Belgian Bone Club. Osteoporos Int 18: 1439-1450, 2007.

13 Hanahan D and Weinberg RA: Hallmarks of Cancer. Cell 100(1): 57-70, 2000.

14 Jiang M, Huang O, Zhang X, Xie Z, Shen A, Liu H, Geng M and Shen K: Curcumin induces cell death and restores Tamoxifen sensitivity in the antiestrogen-resistant breast cancer cell lines MCF-7/LCC2 and MCF-7/LCC9. Molecules 18(1): 701-720, 2013.

15 Anighoro A, Bajorath J and Rastelli G: Polypharmacology: Challenges and Opportunities in drug discovery. J Med Chem 57: 7874-7887, 2014.

16 Kunnumakkara AB, Anand P and Aggarwal BB: Curcumin inhibits proliferation, invasion, angiogenesis and metastasis of different cancers through interaction with multiple cell signalling proteins. Cancer Lett 269: 199-225, 2008.

17 Lai HW, Chien SY, Kuo SJ, Tseng LM, Lin HY, Chi CW and Chen DR: The potential utility of curcumin in the treatment of Her-2-overexpressed breast cancer: an in vitro and in vivo comparison study with herceptin. Evid Based Complement Alternat Med 2012: 486568, 2012.

18 Cridge BJ, Larsen L and Rosengren RJ: Curcumin and its derivatives in breast cancer: Current developments and potential for the treatment of drug-resistant cancers. Oncol Disc 1: 6, 2013.

19 Sharma RA, Gescher AJ and Steward WP: Curcumin: The story so far. Eur J Cancer 41: 1955-1968, 2005.

20 Nelson KM, Dahlin JL, Bisson J, Graham J, Pauli GF and Walters MA: The essential medicinal chemistry of curcumin. J Med Chem 60(5): 1620-1637, 2017.

21 Burgos-Moron E, Calderon-Montano JM, Salvador J, Robles A and Lopez-Lazaro M: The dark side of curcumin. Int J Cancer 126: 1771-1775, 2010.

22 Lopez-Lazaro M: Anticancer and carcinogenic properties of curcumin: considerations for its clinical development as a cancer chemopreventive and chemotherapeutic agent. Mol Nut Food Res 52: S103-S127, 2008.

23 Heger M: Drug screening: Don't discount all curcumin trial data. Nature 543: 40, 2017.

24 Notarbartolo M, Poma P, Perri D, Dusonchet L, Cervello M and D'Alessandro N: Antitumour effects of curcumin, alone or in combination with cisplatin or doxorubicin, on human hepatic cancer cells - Analysis of their possible relationship to changes in NFKB activation levels and in IAP gene expression. Cancer Lett 224: 53-65, 2005.

25 Chandran B and Goel A: A randomized, pilot study to assess the efficacy and safety of curcumin in patients with active rheumatoid arthritis. Phytother Res 26: 1719-1725, 2012.

26 Funamoto M, Sunagawa Y, Katanasaka Y, Miyazaki Y, Imaizumi A, Kakeya H, Yamakage H, Satoh-Asahara N, Komiyama M, Wada H, Hasegawa K and Morimoto T: Highly absorptive curcumin reduces serum atherosclerotic low-density lipoprotein levels in patients with mild COPD. Int J Chronic Obstruct Pulm Dis 11: 2029-2034, 2016. 
27 Padmanaban G and Rangarajan PN: Curcumin as an adjunct drug for infectious diseases. Trends Pharmacol Sci 37: 1-3, 2016.

28 de Moraes TA, Filha MJ, Camara CA, Silva TM, Soares BM, Bomfim IS, Pessoa C, Ximenes GC and Silva Junior VA: Synthesis and cytotoxic evaluation of a series of 2-aminonaphthoquinones against human cancer cells. Molecules 19(9): 13188-13199, 2014.

29 Davids H, Theunissen R, Chakravorty S, Mohammed R, Frost $\mathrm{C}$, van Otterlo WAL and de Koning CB: Aminonaphthoquinones as potential anti-breast cancer agents. Afr J Pharm Pharmacol 6(45): 3102-3112, 2012.

30 Davison C (unpublished). Nelson Mandela Metropolitan University, South Africa.

31 Chou TC and Talalay P: Quantitative analysis of dose-effect relationships: the combined effects of multiple drugs or enzyme inhibitors. Adv Enzyme Regul 22: 27-55, 1984.

32 Pratt SE and Pollak MN: Estrogen and antiestrogen modulation of MCF-7 human breast cancer cell proliferation is associated with specific alterations in accumulation of insulin-like growth factor binding proteins in conditioned media. Cancer Res 53: 5193-5198, 1993.

33 Seibel MJ: Biochemical markers of bone turnover Part I: Biochemistry and variability. Clin Biochem Rev 26: 97-122, 2005.

34 Albert JL, Sundstrom SA and Lyttle CR: Estrogen regulation of placental alkaline phosphatase gene expression in a human endometrial adenocarcinoma cell line. Cancer Res 50: 3306$3310,1990$.

35 Holinka CF, Hata H, Kuramoto H and Gurpide E: Effects of steroid hormones and antisteroids on alkaline phosphatase activity in human endometrial cancer cells (Ishikawa line). Cancer Res 46: 2771-2774, 1986.

36 Mathew N, Karunan T, Srinivasan L and Muthuswamy K: Synthesis and screening of substituted 1, 4-naphthoquinones (NPQs) as antifilarial agents. Drug Dev Res 71: 188-196, 2010.

37 Bhattacharyya S: 2-Chloro-3-(4-morpholino)-1,4-naphthoquinone. Molecules 5: M160, 2000.

38 Soto AM, Sonnenschein C, Chung KL, Fernandez MF, Olea N and Serrano FO: Research Article: The E-Screen assay as a tool to identify estrogens: an update on estrogenic environmental pollutants. Environ Health Perspect 103(Suppl 7): 113-122, 1995

39 Mosmann T: Rapid colorimetric assay for cellular growth and survival: application to proliferation and cytotoxicity assays. J Immunol Methods 65(1-2): 55-63, 1983.
40 Danhof M, de Jongh J, De Lange EC, Della Pasqua O, Ploeger BA and Voskuyl RA: Mechanism-based pharmacokineticpharmacodynamic modeling: biophase distribution, receptor theory, and dynamical systems analysis. Annu Rev Pharmacol Toxicol 47: 357-400, 2007.

41 Zhao L, Wientjes MG and Au JL: Evaluation of combination chemotherapy: integration of nonlinear regression, curve shift, isobologram, and combination index analyses. Clin Cancer Res 10: 7994-8004, 2004.

42 Greco WR, Bravo G and Parsons JC: The search for synergy: a critical review from a response surface perspective. Pharmacol Rev 47(2): 331-385, 1995.

43 Basu-Roy U, Basilico C and Mansukhani A: Osteogenic and adipogenic differentiation of osteosarcoma cells. Bio-protocol 2(24): e308, 2012.

44 Sparks JW and Brautigan DL: Specificity of protein phosphotyrosine phosphatase. J Biol Chem 260: 2042-2045, 1985.

45 Suzuki M, Kuramoto H, Hamano M, Shirane H and Watanabe $\mathrm{K}$ : Effects of oestradiol and progesterone on the alkaline phosphatase activity of a human endometrial cancer cell-line. Acta Endocrinol (Copenh) 93: 108-113, 1980.

46 Pacheco-Pantoja EL, Ranganath LR, Gallagher JA, Wilson PJ and Fraser WD: Receptors and effects of gut hormones in three osteoblastic cell lines. BMC Physiol 11(12): 1-14, 2011.

47 Hoemann $\mathrm{CD}$, El-Gabalawy $\mathrm{H}$ and McKee $\mathrm{MD}$ : In vitro osteogenesis assays: Influence of the primary cell source on alkaline phosphatase activity and mineralization. Pat Biol 57: 318-323, 2009.

48 Mohseny AB, Machado I, Cai Y, Schaefer KL, Serra M, Hogendoorn PCW, Llombart-Bosch A and Cleton-Jansen AM: Breast, skin, soft tissue and bone, functional characterization of osteosarcoma cell lines provides representative models to study the human disease. Lab Invest 91: 1195-1205, 2011.

49 Shao ZM, Shen ZZ, Liu CH, Sartippour MR, Go VL, Heber D and Nguyen M: Curcumin exerts multiple suppressive effects on human breast carcinoma cells. Int J Cancer 98(2): 234-240, 2002.
Received April 6, 2017

Revised May 6, 2017

Accepted May 11, 2017 